\title{
Intravenous amino acid therapy for kidney protection in cardiac surgery patients: A pilot randomized controlled trial
}

\author{
Hong Pu, MD, ${ }^{\text {a,b }}$ Gordon S. Doig, PhD, ${ }^{a}$ Philippa T. Heighes, PhD, ${ }^{a}$ Matilde J. Allingstrup, PhD, ${ }^{a}$ \\ Andy Wang, FANZCA, ${ }^{\mathrm{c}}$ John Brereton, FRACS, ${ }^{\mathrm{c}}$ Carol Pollock, PhD, ${ }^{\mathrm{c}}$ Douglas Chesher, $\mathrm{PhD},{ }^{\mathrm{d}}$ and \\ Rinaldo Bellomo, FCICM ${ }^{\mathrm{e}, \mathrm{f}}$
}

\section{ABSTRACT}

Objective: To determine whether a continuous intravenous infusion of standard amino acids could preserve kidney function after on-pump cardiac surgery.

Methods: Adult patients scheduled to receive cardiac surgery lasting longer than 1 hour on-pump were randomized to standard care $(n=36)$ or an infusion of amino acids initiated immediately after induction of anesthesia $(n=33)$. The study's primary outcome measurements assessed renal function. These assessments included duration of renal dysfunction, duration and severity of acute kidney injury (AKI), estimated glomerular filtration rate (eGFR) over time, urine output, and use of renal-replacement therapy. Complications and other measures of morbidity were also assessed.

Results: Sixty-nine patients (mean age 71.5 [standard deviation 9.2] years; 19 of 69 women) were enrolled and randomized. Patients received coronary artery bypass graft surgery (37/69), valve surgery (24/69), coronary artery bypass graft and valve surgery (6/69), or other procedures (2/69). Mean on-pump time was 268 [standard deviation 136] minutes. Duration of renal dysfunction did not differ between the groups (relative risk, $0.86 ; 95 \%$ confidence interval [CI], $0.19-3.79, P=.84)$. However, patients who received the amino acid infusion had a reduced duration of AKI (relative risk, $0.02 ; 95 \%$ CI, 0.005-0.11, $P<.0001)$ and greater eGFR $(+10.8 \%$; 95\% CI, $1.0 \%-20.8 \%, P=.033)$. Daily mean urine output was also significantly greater in patients who received the amino acid infusion $(1.4 \pm 0.5$ vs $1.7 \pm 0.9 \mathrm{~L} / \mathrm{d} ; P=.046)$.

Conclusions: Commencing an infusion of standard amino acids immediately after the induction of anesthesia did not alter duration of renal dysfunction; however, other key measures of renal function (duration of AKI, eGFR and urine output) were significantly improved. These results warrant replication in multicenter clinical trials. (J Thorac Cardiovasc Surg 2019;157:2356-66)

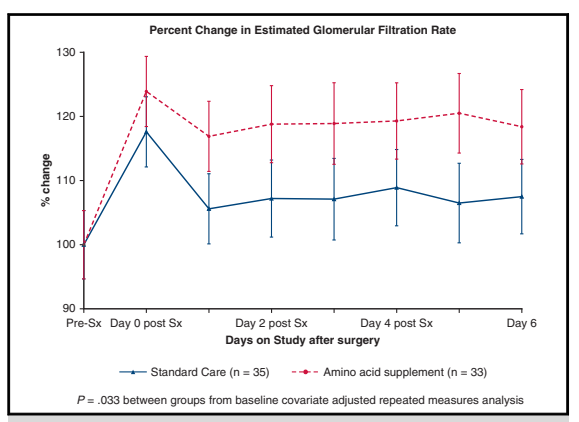

Estimated glomerular filtration rate by study day for patients randomly allocated to receive a continuous infusion of amino acids or standard care: percent change from presurgery baseline.

\section{Central Message}

Cardiac surgery-associated acute kidney injury may be prevented by commencing an intravenous infusion of standard amino acids immediately after induction of anesthesia.

\section{Perspective}

Cardiopulmonary bypass impairs renal oxygenation by inducing an increase in renal vascular resistance that results in reduced renal blood flow, even when cardiac index is increased. After healthy adults eat a highprotein meal, afferent arteriolar vasodilatation occurs, which increases renal blood flow. Protein intake initiated during bypass surgery may ameliorate the onset of acute kidney injury.

See Commentary on page 2367.

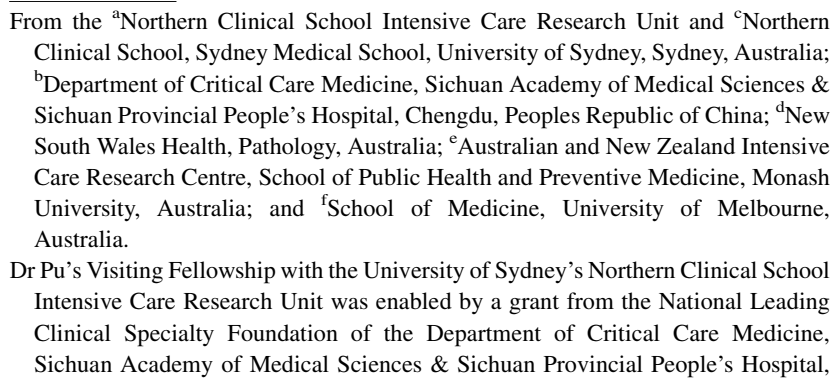

Chengdu, Peoples Republic of China. This work was supported by peerreviewed academic grants from the Heart Research Australia (formerly North Shore Heart Research Foundation) Grant Number 2012-01 and the University of Sydney's Cardiothoracic Research Scheme. Baxter Healthcare Pty, Ltd, supplied the study amino acids.

Received for publication May 21, 2018; revisions received Nov 7, 2018; accepted for publication Nov 8, 2018; available ahead of print Jan 23, 2019.

Address for reprints: Gordon S. Doig, PhD, Royal North Shore Hospital, Intensive Care Unit, St. Leonards, Australia 2065 (E-mail: gdoig@med.usyd.edu.au). $0022-5223 / \$ 36.00$

Copyright (C) 2018 by The American Association for Thoracic Surgery https://doi.org/10.1016/j.jtcvs.2018.11.097 


\section{Abbreviations and Acronyms \\ AKI = acute kidney injury \\ $\mathrm{CI}=$ confidence interval \\ CONSORT $=$ Consolidated Standards of Reporting Trials \\ $\mathrm{CPB}=$ cardiopulmonary bypass \\ eGFR = estimated glomerular filtration rate \\ GFR = glomerular filtration rate \\ HDU = high-dependency unit \\ ICU = intensive care unit \\ RCT $=$ randomized controlled trial \\ RRT = renal-replacement therapy \\ $\mathrm{SD} \quad=$ standard deviation}

Acute kidney injury (AKI) has become one of the most common complications after cardiac surgery, with up to $40 \%$ of all patients developing AKI at some time during their recovery. ${ }^{1}$ While the onset of AKI after cardiac surgery is associated with a 10-fold increase in mortality, caring for patients with cardiac surgery-associated AKI increases hospital costs to the US health care system by $\$ 1.01$ billion per year. $^{2}$ Despite these huge health and cost implications, there are no reliable means to treat cardiac surgery-associated AKI. ${ }^{3}$

On-pump cardiac surgery presents significant challenges to the maintenance of normal renal function. Exposure to cardiopulmonary bypass (CPB) impairs renal oxygenation by inducing an increase in renal vascular resistance that results in a redistribution of blood flow away from the kidney, even when cardiac index is increased. ${ }^{4}$ In addition, hypothermia, hemodilution, hypotension, hemolysis, and low-flow cardiac output states all have direct and independent effects that reduce renal blood flow by increasing renal vascular resistance. ${ }^{3}$ Ischemic and inflammatory stress arising from reduced renal blood flow have been proposed as major contributors toward the onset of cardiac surgery-associated AKI. ${ }^{5}$

Eating a high-protein meal is known to have a major influence on renal hemodynamics. High-protein intake results in afferent arteriolar vasodilatation and a decrease in renal vascular resistance with a consequent increase in renal blood flow. ${ }^{6,7}$ In response, glomerular filtration rate (GFR) increases by up to $35 \%$ over resting baseline GFR. $^{8,9}$
The kidney's normal hyperemic response to protein intake can be viewed teleologically as a mechanism developed to enhance the elimination of nitrogenous wastes arising from a protein meal. ${ }^{7}$ This response to protein intake is conserved across many species of mammals, ${ }^{7,10}$ and multiple local and systemic mechanisms have been proposed as modulators. ${ }^{11}$ Although it is accepted that protein intake alters single-nephron GFR via the tubuloglomerular feedback mechanism, protein intake alters overall renal vascular resistance through local receptors (N-methyl-D-aspartate glutamate receptor) and humoral factors (nitric oxide, insulin, glucagon, prostaglandins, etc). ${ }^{12}$ Understanding of the necessary and sufficient interactions between each specific mechanism is evolving but remains incomplete. ${ }^{11,12}$

A randomized controlled trial (RCT) conducted in 22 adult patients undergoing cardiac surgery demonstrated that an infusion of amino acids commenced immediately after surgery can significantly increase renal blood flow, GFR, and renal oxygen consumption in this patient population. ${ }^{13}$ Animal models show that the resultant increase in renal blood flow after a protein meal can protect the kidney from acute ischemic insults. ${ }^{10}$ We hypothesized that an infusion of amino acids, commenced before exposure to $\mathrm{CPB}$, may help maintain renal blood flow, thus ameliorating the ischemic and inflammatory injury that contributes toward the onset of cardiac surgery-associated AKI. We conducted this pilot parallel RCT to test this hypothesis. Patients were randomly allocated to standard care or to commence an infusion of amino acids after induction of anesthesia.

\section{METHODS}

This single-center study was conducted at the Royal North Shore Hospital, Sydney, Australia. Approval was obtained from the participating site's Human Research Ethics Committee (April 17, 2012: Reference Number 1201-024M, HREC/12/HSWKE/28). The trial is registered in the Australian and New Zealand Clinical Trials Registry (anzctr.org.au ACTRN12612000134820). Patients provided written informed consent before enrollment in accordance with local and national laws. Conduct and reporting are consistent with the 2010 Consolidated Standards of Reporting Trials (CONSORT) extension for pilot trials (Figure E1 and Online Data Supplement 1). ${ }^{14}$

Adult patients who were scheduled to undergo cardiac surgery expected to require longer than 1 hour on-pump were considered eligible. Only patients with current estimated glomerular filtration rate (eGFR) less than $90 \mathrm{~mL} / \mathrm{min} / 1.73 \mathrm{~m}^{2}$ were enrolled, as patients with pre-existing renal compromise are more likely to develop subsequent AKI, thus improving the power of this small pilot project. ${ }^{3}$ If the patient's eGFR was less than $20 \mathrm{~mL} / \mathrm{min} / 1.73 \mathrm{~m}^{2}$, they were not eligible for recruitment. See Online Data Supplements 2 and 3 for complete eligibility criteria.

Allocation concealment was maintained by use of a central randomization web server. eGFR was considered a potentially important baseline prognostic variable. To prevent extreme imbalance, 2 strata were defined by eGFR at time of randomization based on whether eGFR was greater than or less than $30 \mathrm{~mL} / \mathrm{min} / 1.73 \mathrm{~m}^{2}$ and the randomization was conducted separately within each stratum. The sequence was generated to achieve a $1: 1$ allocation ratio using blocks of variable size with random seeds. ${ }^{15}$ 
Investigators were required to attend a small-group start-up meeting and complete a formal study run-in phase to become familiar with the application of eligibility criteria and use of the dosing algorithm before recruiting their first patient. ${ }^{16}$

\section{Interventions}

If randomized to the intervention arm, the patient received a continuous infusion of a standard mixture of L-amino acids (Synthamin 17 Electrolyte Free; Baxter Healthcare, Sydney, Australia) delivered at a rate of $42 \mathrm{~mL} / \mathrm{h}$ to achieve a daily protein intake of at least $100 \mathrm{~g} /$ day. This dose of intravenous amino acids has previously been shown to result in a significant and marked increase in GFR in healthy elderly adults. ${ }^{8}$ The infusion was begun after anesthetic induction and was administered through a dedicated central line and commenced at the time the central line was placed. The infusion continued until the patient was discharged from the intensive care unit (ICU)/high-dependency unit (HDU) to the ward.

If the patient commenced any form of nutritional support while in the ICU/HDU, the infusion rate of the study L-amino acid intervention was reduced such that the total protein intake from all sources (nutrition and study intervention) was $2.0 \mathrm{~g} / \mathrm{kg} / \mathrm{day}$. The study intervention was not blinded. Complete details of the dosing algorithm are provided in Online Data Supplement 2.

Standard care was defined pragmatically. In both the study intervention and the standard care group, the attending clinician determined all aspects of intraoperative and postoperative care, including anesthetic regimen, CPB parameters, fluid replacement, and nutrition support based on their standard practice and individual patient's needs, independent of the study intervention. Additional information regarding intraoperative care is presented in Online Data Supplement 2.

\section{Primary Outcomes: Measures of Renal Function}

The primary measure of renal function was defined a priori as the duration of renal dysfunction after surgery using the validated threshold for clinically significant renal dysfunction determined by the Brussels Table (creatinine $>168 \mu \mathrm{mol} / \mathrm{L}$ ), ${ }^{17}$ which is equivalent to a Sepsis-related Organ Failure Assessment renal domain score greater than $1 .{ }^{18}$ Efficacy was also assessed by analyzing the duration of AKI after surgery, defined and staged using the Kidney Disease: Improving Global Outcomes criteria. ${ }^{19}$ Duration was defined as the total number of days after onset whereby the worst (greatest) creatinine value available during each calendar day on study met the prespecified criteria for renal dysfunction or AKI.

Additional measures of renal function included eGFR calculated from serum creatinine using the Chronic Kidney Disease Epidemiology Collaboration equation, developed by Levey and colleagues ${ }^{20}$; eGFR, calculated from serum cystatin $\mathrm{C}$ using the equations developed by Stevens and colleagues ${ }^{21}$; and use of renal-replacement therapy (RRT).

\section{Secondary Outcomes: Measures of Morbidity}

Secondary outcomes included measures of intraoperative and postoperative care (duration of surgery, crossclamp time, ICU stay, hospital stay, mechanical ventilation days, etc) and patient-centered outcomes (vital status at study day 90; Zubrod/World Health Organization Performance Status $^{22}$; RAND-36 General Health Status Ver 1; RAND-36 Physical Function scale Ver 1$){ }^{23}$

\section{Creatinine and Cystatin C Assays}

Creatinine was assayed using the Abbott Architect Jaffe method. The assay has a coefficient of variation of $2.1 \%$ at $70 \mu \mathrm{mol} / \mathrm{L}$ and $1.7 \%$ at $510 \mu \mathrm{mol} / \mathrm{L}$. Samples for creatinine assay were routinely collected on each day of ICU/HDU and hospital admission.

Serum cystatin $C$ was assayed using the particle-enhanced turbidimetric immunoassay on the Abbott Architect c4000 chemistry analyzer (Abbott,
Abbott Park, Ill). The cystatin $\mathrm{C}$ assay has a coefficient of variation of $3.5 \%$ at $0.34 \mathrm{mg} / \mathrm{L}, 3.6 \%$ at $0.58 \mathrm{mg} / \mathrm{L}, 2.7 \%$ at $0.88 \mathrm{mg} / \mathrm{L}$, and $3.6 \%$ at $4.2 \mathrm{mg} / \mathrm{L}$. To reduce sample collection, handling, and processing costs, a skip pattern was used to optimize information gain: samples for cystatin $\mathrm{C}$ assay were obtained every second day for the first week and every third day thereafter, up to study day 16 .

\section{Sample Size, Power, and Statistical Analysis}

Sample size estimation calculated 72 patients would be required to provide $80 \%$ power to detect a reduction in duration of renal dysfunction between groups of 2.2 days, assuming a variance of 11 days. Estimates of the potential treatment effect and variance were obtained from previously collected data demonstrating a reduction in duration of renal dysfunction in general critically ill patients attributable to improved protein intake ${ }^{24}$ and are based on data from the subset of cardiac surgery patients enrolled in this larger trial, which also showed significant benefit.

Analysis of the effect of treatment on the primary outcome and other count data (hospital stay, ICU/HDU stay, duration of ventilation, duration of RRT, etc) was conducted using Poisson regression adjusted for time at risk (hospital stay) using an offset term where appropriate. When an offset term was employed, outcomes are presented as count per 10 hospital days. If the scaled deviance exceeded 1.4 units per degree of freedom, a conservative negative-binomial model was employed. A prespecified algorithm was used to identify baseline characteristics for inclusion in a covariate adjusted regression model to control for confounding. ${ }^{25}$

Repeated measures over time, such as eGFR or urea, were assessed using a nested analysis of variance, controlling for baseline values of the repeated measure. Dichotomous outcomes were assessed using an exact Pearson $\chi^{2}$ test, with unconditional exact $95 \%$ confidence intervals (CI) calculated around the risk difference. Under the Central Limit Theorem, given that samples of continuous biological variables arise from populations with finite means and finite variances, continuous biological variables were analyzed using $t$-tests and presented as mean and standard deviation (SD).

All analysis was conducted under the principle of intention to treat. All analytic decision thresholds were declared a priori in a previously published statistical analysis plan. ${ }^{25}$ A 2 -sided $P$-value less than .05 was accepted to indicate statistical significance. Analysis was conducted in SAS version, 9.2 (SAS Institute, Cary, NC).

\section{RESULTS}

From March 5, 2013, to April 26, 2016, 73 adult patients scheduled to undergo elective or urgent on-pump cardiothoracic surgery at the Royal North Shore Hospital, Sydney, Australia, provided consent to participate. Two consented patients became ineligible before surgery (1 surgery cancelled and 1 fluid intake restricted to less than $1 \mathrm{~L}$ per day) and were not randomized. Of the 71 patients who were randomized before surgery, 2 were rescheduled to receive surgery off-pump and were therefore not eligible for enrollment. Figure 1 presents a CONSORT patient flow diagram.

\section{Baseline Balance}

The mean age of enrolled patients was 71.5 years, with an SD of 9.2 years. Fifty-four percent (37/69) of enrolled patients had coronary artery bypass graft surgery only, $34.7 \%(24 / 69)$ had valve surgery only, $8.7 \%(6 / 69)$ had coronary artery bypass graft plus valve surgery, and $2.9 \%$ $(2 / 69)$ had other procedures. Sixteen percent $(11 / 69)$ of 


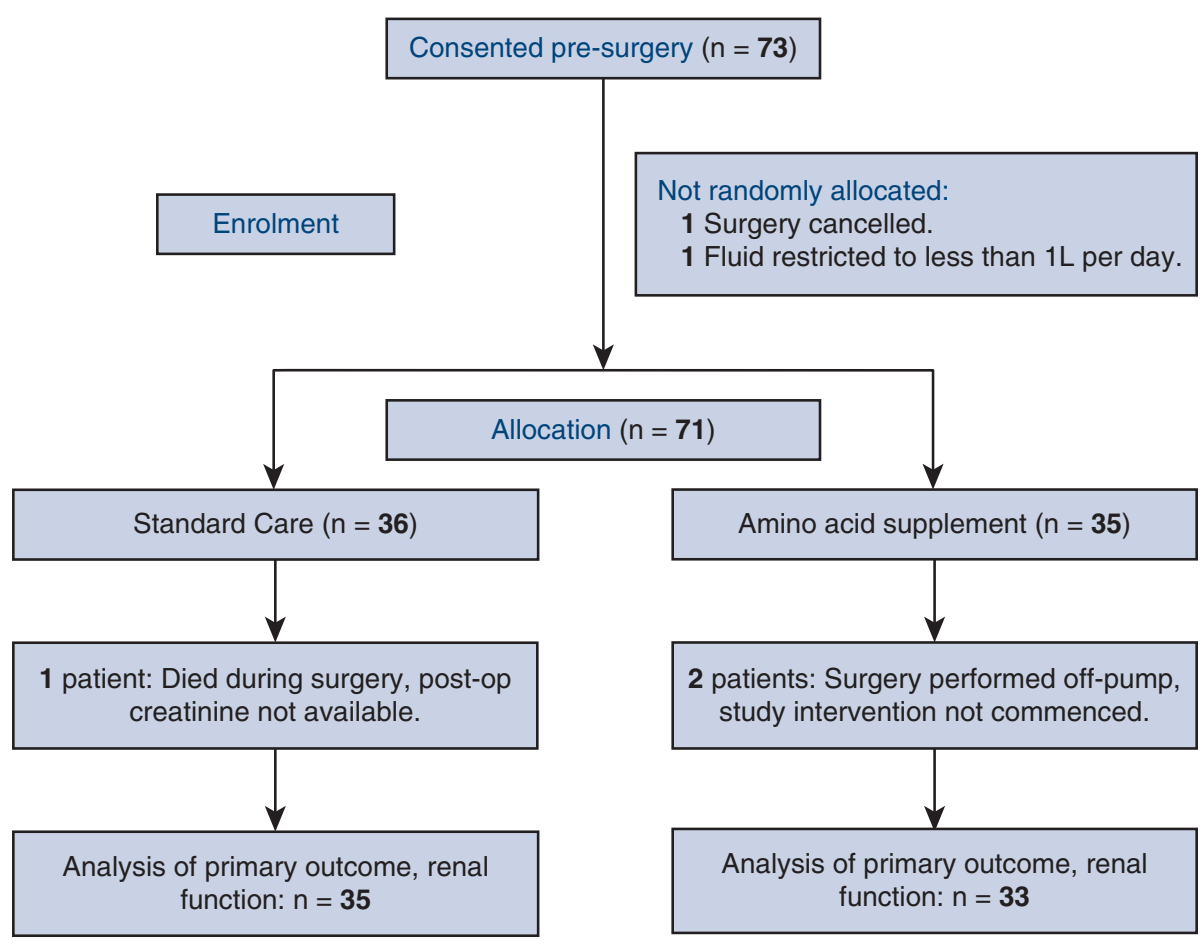

Note: The study budget was not sufficient to support the collection of complete information on all patients screened for eligibility into the trial.

The total number of screened patients, and reasons they were not enrolled, are not available.

FIGURE 1. The Consolidated Standards of Reporting Trials 2010 Patient Recruitment Flow Diagram. Number of patients consented, randomly allocated, followed up, and analyzed.

patients had previous cardiac surgery. By chance, significantly more female patients (5/36 vs $14 / 33$, $P=.01)$ were randomly allocated to the study intervention group. No other baseline characteristics exhibited significant imbalance. Additional demographics and patient characteristics are presented in Table 1.

\section{Study Process Measures}

One hundred percent (33/33) of enrolled patients allocated to the study intervention group received supplementary amino acids during their on-pump procedure. During surgery, the mean duration of the $42 \mathrm{~mL} / \mathrm{h}$ infusion was 318 (SD 99) minutes, resulting in the delivery of 223 (SD 69) mL of study amino acids. Study intervention patients received significantly more protein on postoperative day 0 ; day 1 ; and day 2 compared with standard care patients (Figure E2 in Online Data Supplement 2). No serious adverse events were reported.

\section{Primary Outcomes: Measures of Renal Function}

There was no significant difference with regard to the primary measure of renal function, duration of renal dysfunction, when standard care was compared with the amino acid supplement group ( 0.65 vs 1.02 renal dysfunction days per 10 hospital days, $95 \% \mathrm{CI},-0.46$ to 5.01 days, $P=.60$, Table 2). Covariate adjusted analysis also did not find any significant differences between groups (relative risk, 0.86; 95\% CI, 0.19-3.79, $P=.84$, Table 2 and Table E1).

Univariate analysis demonstrated a significant reduction in the duration of cardiac surgery-associated AKI attributable to the study amino acid supplement ( 0.45 vs 0.08 days of AKI per 10 hospital days, $95 \% \mathrm{CI},-0.43$ to -0.04 days, $P=.037$, Table 2). Covariate-adjusted analysis confirmed the presence of this significant treatment effect (RR, 0.02; 95\% CI, 0.005-0.11, $P<.0001$, Table 2 and Table E2).

Estimated from serum creatinine-based equations, ${ }^{20}$ repeated measures analysis demonstrated eGFR was significantly greater than baseline over the first 7 study days for patients receiving supplementary amino acids compared with standard care $(+10.8 \%$ difference; $95 \%$ CI, $1.0 \%-20.8 \%, P=.033$, Figure 2). Estimated from serum cystatin C-based equations, ${ }^{21}$ repeated measures analysis did not reach statistical significance $(+5.0 \%$ difference; $95 \% \mathrm{CI},-5.2 \%$ to $15.1 \%, P=.35$, Figure E3 in Online Data Supplement 2). Cystatin C assay 
TABLE 1. Baseline demographics and characteristics

\begin{tabular}{|c|c|c|}
\hline Patient characteristics & Standard care, 36 patients & Amino acid supplement, 33 patients \\
\hline Age, y, mean (SD) & $70.8(9.0)$ & $72.3(9.5)$ \\
\hline Sex, female, $n(\%)^{*}$ & $5(13.9 \%)$ & $14(42.4 \%)$ \\
\hline Weight, kg, mean (SD) & $86.2(16.2)$ & $88.8(17.2)$ \\
\hline \multicolumn{3}{|l|}{ Measures of kidney function } \\
\hline Creatinine, $\mu \mathrm{mol} / \mathrm{L}$, mean $(\mathrm{SD})$ & $105.2(31.1)$ & $114.1(39.0)$ \\
\hline Renal dysfunction at baseline, creatinine $>168 \mu \mathrm{mol} / \mathrm{L}, \mathrm{n}(\%)$ & $1(2.8)$ & $4(12.1)$ \\
\hline Estimated GFR creatinine, $\mathrm{mL} / \mathrm{min} / 1.73 \mathrm{~m}^{2}$, mean $(\mathrm{SD}) \dagger, \ddagger$ & $64.4(18.6)$ & $55.7(20.2)$ \\
\hline Estimated GFR cystatin $\mathrm{C}, \mathrm{mL} / \mathrm{min} / 1.73 \mathrm{~m}^{2}$, mean $(\mathrm{SD}) \ddagger, \S$ & $55.6(18.3)$ & $45.7(18.1)$ \\
\hline History of CKD (stage 1 or greater), n $(\%) \dagger, \|$ & $16(44.4)$ & $22(66.7)$ \\
\hline \multicolumn{3}{|l|}{ Known risk factors for renal dysfunction, $\mathrm{n}(\%)$} \\
\hline Nephrotoxic agent or pigment, over previous $24 \mathrm{~h}$ & $0(0)$ & $0(0)$ \\
\hline Oliguria, over previous $24 \mathrm{~h}$ & $0(0)$ & $1(3.0)$ \\
\hline Massive transfusion, over previous $24 \mathrm{~h}$ & $0(0)$ & $0(0)$ \\
\hline Obstructive uropathy, over previous $24 \mathrm{~h}$ & $0(0)$ & $0(0)$ \\
\hline \multicolumn{3}{|l|}{ Comorbidities, n (\%) } \\
\hline Hypertension, n (\%) & $33(91.7)$ & $29(87.9)$ \\
\hline Diabetes requiring insulin treatment, $\mathrm{n}(\%)$ & $5(13.9)$ & $7(21.2)$ \\
\hline Recent myocardial infarction, $\mathrm{n}(\%)$ & $12(33.3)$ & $7(21.2)$ \\
\hline Chronic lung disease, $\mathrm{n}(\%)$ & $2(5.6)$ & $5(15.1)$ \\
\hline Peripheral vascular disease, $\mathrm{n}(\%) \dagger$ & $10(27.8)$ & $3(9.1)$ \\
\hline Any previous cardiac surgery, $\mathrm{n}(\%)$ & 7 (19.4) & $4(12.1)$ \\
\hline Congestive heart failure, $\mathrm{n}(\%) \Phi$ & $22(61.1)$ & $24(72.7)$ \\
\hline NYHA class I, n (\%) $†$ & $10(45.5)$ & $5(20.1)$ \\
\hline NYHA class II, n (\%) & $9(40.9)$ & $10(41.7)$ \\
\hline NYHA class III, n (\%) & $3(13.6)$ & $9(17.5)$ \\
\hline NYHA class IV, n $(\%)$ & $0(0)$ & $0(0)$ \\
\hline Most recent LVEF, if recorded before surgery & $56.9(9.6) \mathrm{n}=32$ & $56.1(9.5) \mathrm{n}=28$ \\
\hline \multicolumn{3}{|l|}{ Preoperative medications, $\mathrm{n}(\%)$} \\
\hline Vasoactive drugs & $1(2.8)$ & $0(0)$ \\
\hline NSAID (including aspirin $>160 \mathrm{mg} /$ day) & $1(2.8)$ & $3(9.1)$ \\
\hline ACE inhibitor & $10(27.8)$ & $5(15.1)$ \\
\hline Proximal or distal loop diuretic & $6(16.7)$ & $8(24.2)$ \\
\hline COX-2 inhibitor & $0(0)$ & $0(0)$ \\
\hline \multicolumn{3}{|l|}{ Urgency of cardiac surgery, $\mathrm{n}(\%)$} \\
\hline Elective & $21(58.3)$ & $24(72.7)$ \\
\hline Urgent & $15(41.7)$ & $9(27.3)$ \\
\hline Emergency & $0(0)$ & $0(0)$ \\
\hline Salvage & $0(0)$ & $0(0)$ \\
\hline \multicolumn{3}{|l|}{ Type of surgery, $\mathrm{n}(\%) \dagger$} \\
\hline CABG only & $23(63.9)$ & $14(42.4)$ \\
\hline Valve only & $9(25)$ & $15(45.5)$ \\
\hline Valve + CABG & $4(11.1)$ & $2(6.0)$ \\
\hline Other procedure & $0(0)$ & $2(6.0)$ \\
\hline \multicolumn{3}{|l|}{ Type of valve surgery, $n(\%)$} \\
\hline Mitral valve replacement & $3(8.6)$ & $3(9.1)$ \\
\hline Mitral valve repair & $1(2.9)$ & $2(6.1)$ \\
\hline Aortic valve replacement & $9(25.7)$ & $13(39.4)$ \\
\hline Aortic valve repair & $1(2.9)$ & $0(0)$ \\
\hline Pulmonary valve replacement & $0(0)$ & $0(0)$ \\
\hline Pulmonary valve repair & $0(0)$ & $0(0)$ \\
\hline
\end{tabular}




\begin{tabular}{|c|c|c|}
\hline Patient characteristics & Standard care, 36 patients & Amino acid supplement, 33 patients \\
\hline Tricuspid valve replacement & $0(0)$ & $1(3.0)$ \\
\hline Tricuspid valve repair & $0(0)$ & $1(3.0)$ \\
\hline \multicolumn{3}{|c|}{ 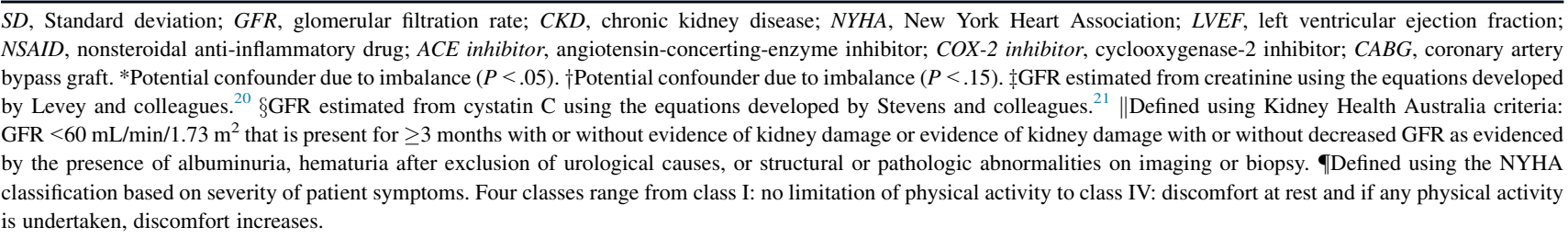 } \\
\hline
\end{tabular}

samples were obtained half as often as samples for serum creatinine.

Although total mean daily fluid intake did not differ between groups $(2.3 \pm 0.5 \mathrm{~L} /$ day vs $2.4 \pm 0.4 \mathrm{~L} /$ day, $P=.21$ ) over the course of the ICU/HDU stay, mean daily urine output was significantly greater in the group of patients who received the amino acid supplement $(1.4 \pm 0.5$ vs $1.7 \pm 0.9 \mathrm{~L} /$ day, $P=.046)$.

Repeated measures analysis revealed significantly greater blood urea levels in patients receiving the amino acid infusion $(8.35 \pm 8.33 \mathrm{mmol} / \mathrm{L}$ vs $11.39 \pm 8.98 \mathrm{mmol} / \mathrm{L}$, $P=.028$, Figure E4 in Online Data Supplement 2); however, there were no significant differences between groups in the use of RRT or any other measures of kidney function (Table 2).

\section{Secondary Outcomes: Measures of Morbidity}

There were no significant differences between groups with regard to survival, postoperative stroke, reoperation, ICU/HDU stay, hospital stay, or any other intraoperative or postoperative outcomes (Table 3).

\section{DISCUSSION}

In this pilot trial, we recruited patients with known presurgical eGFR less than $90 \mathrm{~mL} / \mathrm{min} / 1.73 \mathrm{~m}^{2}$ who were scheduled to receive on-pump cardiac surgery to determine whether a simple and inexpensive amino acid infusion could protect their renal function. Our study process measures demonstrate that the provision of the amino acid infusion is feasible, and compared with the standard care group, achieves a significant increase in protein intake during the first 3 postoperative days. Although we found no significant effect on our primary measure of renal function, duration of renal dysfunction, commencing an infusion of standard L-amino acids immediately after the induction of anesthesia led to significant improvements in other key measures of renal function: duration of AKI was reduced, eGFR was improved, and urine output was increased. These improvements in key pre-stated secondary outcomes should be viewed as exploratory; however, they are potentially important and warrant confirmation by the conduct of multicenter clinical trials adequately powered to detect improvements in patient-centered outcomes. See Video 1 for a brief talk about the overall relevance of these findings.

\section{Measures of Renal Function}

In the current study, a continuous infusion of amino acids commenced immediately after the induction of anesthesia and continued until discharge from ICU/HDU to the ward resulted in a sustained $10.8 \%(95 \%$ CI, $1.0 \%-20.8 \%)$ greater improvement in eGFR from baseline compared with patients receiving standard care (Figure 2). Young healthy adults can increase eGFR by $35 \%$ in response to a protein meal containing a dose of amino acids similar to the dose provided in this current pilot project, ${ }^{9}$ whereas healthy elderly subjects may increase eGFR by $15.7 \%$ in response to an infusion of amino acids.

It is accepted that on-pump cardiac surgery exposes patients to numerous moderators and mediators that result in increased renal vascular resistance and reduced renal blood flow, ${ }^{3,4}$ thus predisposing patients to an increased risk of AKI. ${ }^{26}$ Consuming a protein meal has been shown to decrease renal vascular resistance and increase renal blood flow in healthy adults. ${ }^{27}$ Although we did not measure renal vascular resistance or renal blood flow in this pilot RCT, it remains a plausible mechanism of action to explain the documented treatment effects.

The primary measure of renal function used in this study was based on a creatinine threshold $(>168 \mu \mathrm{mol} / \mathrm{L})$ accepted to define clinically significant renal dysfunction in critically ill patients in the ICU. ${ }^{17,18}$ Use of a threshold criteria allowed the assessment of treatment effectiveness in patients with preexisting and new-onset renal dysfunction. In 2013, the Kidney Disease: Improving Global Outcomes criteria defined AKI as "an abrupt decrease in kidney function" and required the documentation of a new-onset change in renal function from an explicitly identified baseline time period. ${ }^{19}$ Failure to find a significant effect on duration of renal dysfunction while documenting a significant reduction in duration of AKI suggests the modest improvement in eGFR documented in this pilot study may not be sufficient to return preexisting renal dysfunction to within normal 
TABLE 2. Measures of renal function

\begin{tabular}{|c|c|c|c|c|}
\hline & $\begin{array}{l}\text { Standard care, } \\
35 \text { patients }\end{array}$ & $\begin{array}{l}\text { Amino acid supplement, } \\
33 \text { patients }\end{array}$ & $\begin{array}{l}\text { Effect magnitude } \\
\quad(95 \% \mathrm{CI})\end{array}$ & $\begin{array}{c}P \\
\text { value }\end{array}$ \\
\hline $\begin{array}{l}\text { Duration of renal dysfunction, creatinine } \\
>168 \mu \mathrm{mol} / \mathrm{L} \text {, per } 10 \text { hospital days } \\
\quad(95 \% \mathrm{CI})\end{array}$ & 0.65 days $(0.27-1.53)$ & 1.02 days $(0.44-2.41)$ & 0.37 days $(-0.46$ to 5.01$)$ & .60 \\
\hline \multicolumn{3}{|c|}{$\begin{array}{l}\text { Covariate adjusted duration of renal dysfunction* creatinine }>168 \mu \mathrm{mol} / \mathrm{L} \text {, } \\
\text { relative risk vs standard care }(95 \% \mathrm{CI})\end{array}$} & $0.85(0.19-3.79)$ & .84 \\
\hline $\begin{array}{l}\text { Duration of } \mathrm{AKI}, \dagger \text { creatinine increase } \\
>26.5 \mu \mathrm{mol} / \mathrm{L} \text { within } 48 \mathrm{~h} \\
\text { or }>1.5 \times \text { baseline within } 7 \text { days of } \\
\text { surgery, per } 10 \text { hospital days }(95 \% \mathrm{CI})\end{array}$ & 0.45 days $(0.19-1.04)$ & 0.08 days $(0.03-0.17)$ & -0.37 days $(-0.43$ to -0.04$)$ & .037 \\
\hline \multicolumn{3}{|c|}{$\begin{array}{l}\text { Covariate adjusted duration of } \mathrm{AKI} \ddagger \text { creatinine increase }>26.5 \mu \mathrm{mol} / \mathrm{L} \text { within } 48 \mathrm{~h} \\
\text { or }>1.5 \times \text { baseline within } 7 \text { days of surgery, relative risk vs standard care }(95 \% \mathrm{CI})\end{array}$} & $0.02(0.005-0.11)$ & $<.0001$ \\
\hline \multicolumn{5}{|c|}{ Severity of AKI, days $(95 \% \mathrm{CI})$, per 10 hospital days $(95 \% \mathrm{CI})$} \\
\hline $\begin{array}{l}\text { Duration of stage } 1 \mathrm{AKI} \text {, creatinine } \\
\text { increase }>26.5 \mu \mathrm{mol} / \mathrm{L} \text { within } 48 \mathrm{~h} \\
\text { or }>1.5 \text { and }<2 \times \text { within } 7 \text { days of } \\
\text { surgery }\end{array}$ & 0.37 days $(0.17-0.83)$ & 0.08 days $(0.03-0.17)$ & -0.29 days $(-0.36$ to -0.00$)$ & .0497 \\
\hline $\begin{array}{l}\text { Duration of stage } 2 \text { AKI, creatinine } \\
\geq 2 \text { and }<3 \times \text { within } 7 \text { days }\end{array}$ & 0.08 days $(0.05-0.14)$ & 0 days $(0$ to 0$)$ & NE & $\mathrm{NE}$ \\
\hline $\begin{array}{l}\text { Duration of stage } 3 \mathrm{AKI} \text {, creatinine } \\
\geq 3 \times \text { or } \geq 353.6 \mu \mathrm{mol} / \mathrm{L} \text { within } \\
7 \text { days }\end{array}$ & 0.04 days $(0.02-0.07)$ & 0 days $(0-0)$ & NE & $\mathrm{NE}$ \\
\hline $\begin{array}{l}\text { Duration of RRT, mean per patient } \\
\qquad(95 \% \mathrm{CI}), \mathrm{ICU} / \mathrm{HDU} \text { days }\end{array}$ & 0.14 days $(0.03-0.60)$ & 0.84 days $(0.20-3.5)$ & 0.70 days $(-0.9$ to 14.6$)$ & .22 \\
\hline $\begin{array}{l}\text { Patients with renal dysfunction, } \\
\text { creatinine }>168 \mu \mathrm{mol} / \mathrm{L}, \%,(\mathrm{n} / \mathrm{N})\end{array}$ & $17.1 \%(6 / 35)$ & $18.2 \%(6 / 33)$ & $1.0 \%(-22.1$ to 24.9$)$ & 1.00 \\
\hline $\begin{array}{l}\text { Patients with AKI, creatinine } \\
>1.5 \times \text { baseline, } \%,(\mathrm{n} / \mathrm{N})\end{array}$ & $20.0 \%(7 / 35)$ & $9.0 \%(3 / 33)$ & $-10.9 \%(-33.3$ to 13.4$)$ & .30 \\
\hline \multicolumn{5}{|l|}{ Severity of AKI, $\%,(n / N)$} \\
\hline Patients with stage 1 AKI & $20.0 \%(7 / 35)$ & $9.0 \%(3 / 33)$ & $-10.9 \%(-33.3$ to 13.4$)$ & .30 \\
\hline Patients with stage 2 AKI & $2.9 \%(1 / 35)$ & $0 \%(0 / 33)$ & $-2.9 \%(-26.6$ to 21.2$)$ & 1.00 \\
\hline Patients with stage 3 AKI & $2.9 \%(1 / 35)$ & $0 \%(0 / 33)$ & $-2.9 \%(-26.6$ to 21.2$)$ & 1.00 \\
\hline Patients receiving RRT, $\%,(\mathrm{n} / \mathrm{N})$ & $2.9 \%(1 / 35)$ & $12.1 \%(4 / 33)$ & $9.3 \%(-3.2$ to 21.7$)$ & .19 \\
\hline Requiring RRT at study day $90, \%(\mathrm{n} / \mathrm{N})$ & $3.0 \%(1 / 33)$ & $0 \%(0 / 31)$ & $-3.0 \%(-27.4$ to 21.8$)$ & 1.00 \\
\hline $\begin{array}{l}\text { Total fluid volume, per patient per } \\
\text { ICU/HDU day, mL, mean (SD) }\end{array}$ & $2304(516)$ & 2447 (407) & $142(-84$ to 369$)$ & .21 \\
\hline $\begin{array}{l}\text { Urine output, per patient per } \\
\text { ICU/HDU day, mL, mean (SD) }\end{array}$ & $1383(478)$ & $1733(858)$ & $349(7-691)$ & .046 \\
\hline $\begin{array}{l}\text { Net fluid balance, per patient per } \\
\text { ICU/HDU day, mL, mean (SD) }\end{array}$ & $921(643)$ & $686(790)$ & $-234(-587$ to 118$)$ & .19 \\
\hline $\begin{array}{l}\text { Oliguria, }<100 \mathrm{~mL} \text { for } 6 \text { consecutive } \mathrm{h} \text {, } \\
\text { mean per patient }(95 \% \mathrm{CI}), \mathrm{ICU} / \mathrm{HDU} \\
\text { days }\end{array}$ & 0.11 days $(0.04-0.27)$ & 0.36 days $(0.15-0.86)$ & 0.24 days $(-0.49$ to 1.93$)$ & .19 \\
\hline $\begin{array}{l}\text { Diuretic use, any loop diuretic, mean per } \\
\text { patient }(95 \% \mathrm{CI}), \text { ICU/HDU days }\end{array}$ & 2.30 days $(1.44-3.62)$ & 1.97 days $(1.24-3.12)$ & -0.31 days $(-1.50$ to 2.66$)$ & .75 \\
\hline
\end{tabular}

$\overline{C I}$, Confidence interval; $A K I$, acute kidney injury; $N E$, not estimable; $R R T$, renal-replacement therapy; $I C U / H D U$, intensive care unit/high-dependency unit; $S D$, standard deviation. *Covariate-adjusted model controlled for confounding due to baseline creatinine, peripheral vascular disease, and the stratification variable, baseline eGFR $<30 \mathrm{~mL} / \mathrm{min} /$ $1.73 \mathrm{~m}^{2}$. †Defined using the Kidney Disease Improving Global Outcomes criteria. Baseline creatinine was established using a presurgical blood sample. $\ddagger$ Covariate-adjusted model controlled for confounding due to baseline renal dysfunction, chronic kidney disease, and the stratification variable, baseline eGFR $<30 \mathrm{~mL} / \mathrm{min} / 1.73 \mathrm{~m}$. 


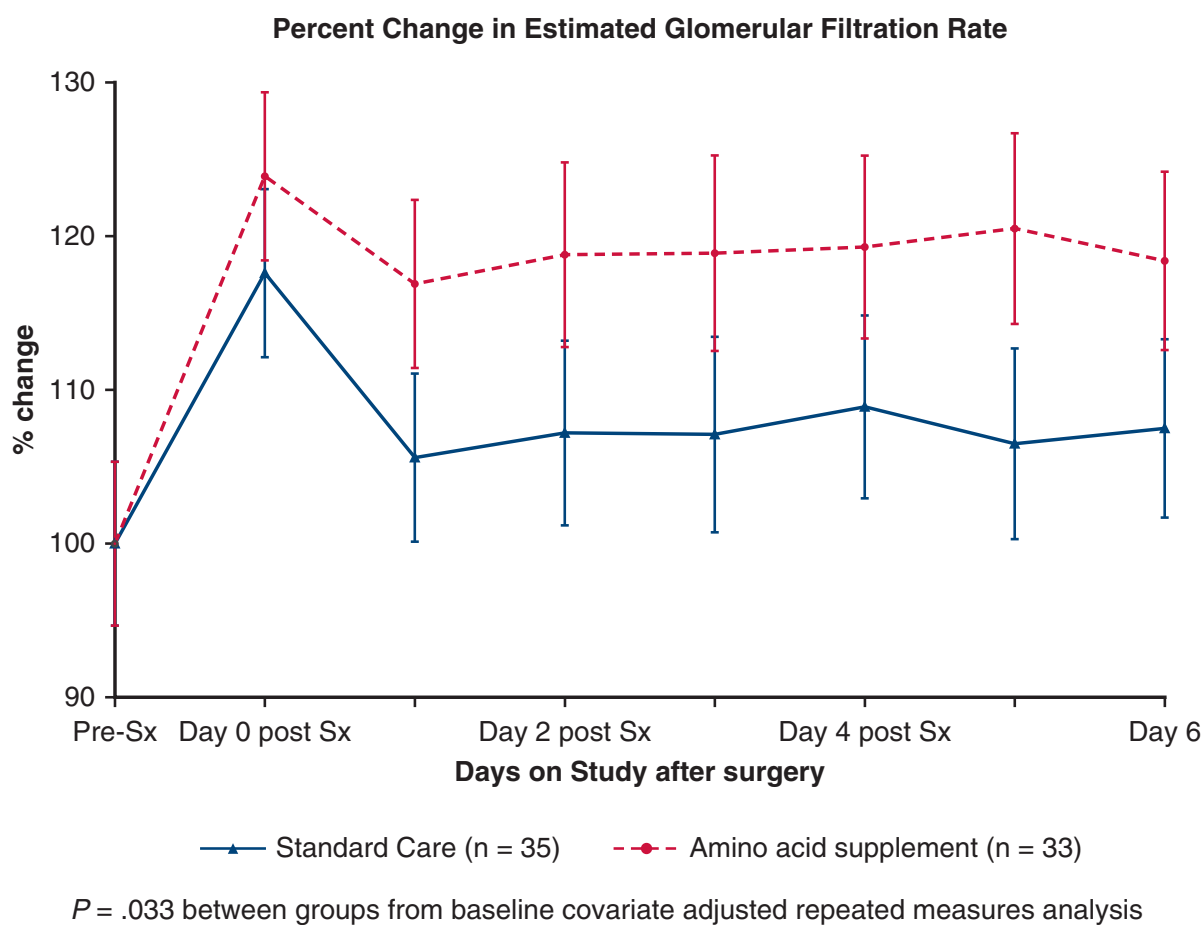

FIGURE 2. Estimated glomerular filtration rate by study day for patients randomly allocated to receive a continuous infusion of amino acids or standard care: percent change from presurgery baseline. Glomerular filtration rate estimated using the Chronic Kidney Disease Epidemiology Collaboration serum creatinine equations developed by Levey and colleagues. ${ }^{20} P=.033$ for between-group difference from baseline covariate-adjusted repeated measures analysis. Error bars indicate $95 \%$ confidence intervals around differences between groups at each time point. Sx, Surgery.

parameters but may be sufficient to confer protection against new-onset kidney injury.

Major observational studies consistently demonstrate that duration of AKI is associated with meaningful patient-centered outcomes. In a cohort of 4987 patients undergoing cardiac surgery, increasing duration of AKI was shown to be significantly associated with decreasing duration of survival over 5-year follow-up: as the observed duration of AKI increased from 2 days to more than 7 days, the death rate doubled during each year of follow-up. ${ }^{28}$ In addition, a 1111-patient study demonstrated that more rapid recovery of renal function after the onset of cardiac surgery-associated AKI was significantly associated with improved 3-year survival, ${ }^{29}$ whereas a 3245 -patient study demonstrated that if cardiac surgery-associated AKI persisted until time of hospital discharge, patients were 15 times more likely to develop chronic kidney disease stage 4 to 5 within 2 years of their surgery. ${ }^{30}$

In the US health care system, the direct hospital costs associated with caring for a cardiac surgery patient who develops $A K I$ are estimated to be $\$ 38,358$ greater than the costs associated with caring for a similar cardiac surgery patient who does not develop AKI. ${ }^{2}$ Furthermore, progression to chronic kidney disease requiring long-term RRT or renal transplantation may increase annual medical costs beyond established willingness-to-pay thresholds. ${ }^{31,32}$
Any reduction in the incidence or duration of AKI may translate to meaningful patient benefits and reduce the consumption of scarce resources.

\section{Strengths and Limitations}

This paper presents the results of a small, single-center pilot RCT. As such, estimates of treatment effects may be overoptimistic and/or unique to the population studied. However, the results demonstrate the study intervention is feasible and has promising effects on multiple measures of renal function. Furthermore, there is no objective evidence to suggest the study population is unique. However, as with all pilot projects, our findings remain exploratory and hypothesis generating. Future research is needed to confirm our results and to determine whether our findings generalize to patient groups not explicitly enrolled in this small pilot RCT.

Two patients were not recruited into the study after randomization because they had procedures rescheduled to off-pump cardiac surgery. The onset of AKI is known to be significantly lower after off-pump cardiac surgery compared with on-pump cardiac surgery. ${ }^{26}$ Thus, the exclusion of these 2 patients is unlikely to bias the results in favor of the study intervention. Furthermore, the study intervention was not commenced in either of these patients because the ethics committee approved protocol 


\begin{tabular}{|c|c|c|c|c|}
\hline & $\begin{array}{l}\text { Standard care, } \\
36 \text { patients }\end{array}$ & $\begin{array}{l}\text { Amino acid supplement, } \\
33 \text { patients }\end{array}$ & $\begin{array}{c}\text { Difference } \\
(\mathbf{9 5} \% \mathbf{C I})\end{array}$ & $\begin{array}{c}P \\
\text { value }\end{array}$ \\
\hline \multicolumn{5}{|l|}{ Intraoperative outcomes } \\
\hline Pump time, min, mean (SD) & $286(147)$ & $248(121)$ & $-38(-101$ to 25$)$ & .24 \\
\hline Crossclamp time, min, mean (SD) & $136(71)$ & $112(52)$ & $-24(-53$ to 5$)$ & .11 \\
\hline Total time of surgery, min, mean (SD) & $373(143)$ & $313(95)$ & $-60(-119$ to 1$)$ & .05 \\
\hline Number of vessels bypassed, if CABG, mean (SD) & $3.4(1.2) n=27$ & $2.8(0.9) \mathrm{n}=16$ & $-0.6(-1.2$ to 0.1$)$ & .07 \\
\hline Vasoactive drug use, $\%(\mathrm{n} / \mathrm{N})$ & $100 \%(36 / 36)$ & $100 \%(33 / 33)$ & $0.0 \%$ & 1.00 \\
\hline Total fluids delivered, mL, mean (SD) & $3333(1983)$ & $2736(1643)$ & $-597(-1467$ to 273$)$ & .18 \\
\hline Study amino acids delivered, mL, mean (SD) & $0(0)$ & $223(69)$ & $223(199-246)$ & N/A \\
\hline Urine output, mL, mean (SD) & $512(327)$ & $624(588)$ & $112(-115$ to 339$)$ & .34 \\
\hline \multicolumn{5}{|l|}{ Postoperative outcomes } \\
\hline ICU stay, days, mean $(95 \%$ CI) & $3.3(2.6-4.0)$ & $4.1(3.3-5.0)$ & $0.8(-0.6$ to 2.9$)$ & .30 \\
\hline HDU stay, days, mean $(95 \% \mathrm{CI})$ & $1.8(1.4-2.3)$ & $1.6(1.3-2.1)$ & $-0.2(-0.8$ to 0.9$)$ & .72 \\
\hline Hospital stay, days, mean $(95 \%$ CI $)$ & $14.4(12.5-16.6)$ & $12.2(10.6-14.0)$ & $-2.2(-5.2$ to 1.8$)$ & .25 \\
\hline Mechanical ventilation, days, mean $(95 \% \mathrm{CI})$ & $2.31(1.83-2.92)$ & $2.39(1.89-3.02)$ & $0.07(-0.81$ to 1.51$)$ & .89 \\
\hline Vasoactive drug use, $\%(\mathrm{n} / \mathrm{N})$ & $100 \%(35 / 35)$ & $96.9 \%(32 / 33)$ & $-3.0 \%(-8.8$ to 3.0$)$ & .48 \\
\hline $\begin{array}{l}\text { Duration of vasoactive drug use, days, mean } \\
\qquad(95 \% \mathrm{CI})\end{array}$ & $3.1(2.7-3.6)$ & $3.1(2.7-3.5)$ & $0.0(-0.8$ to 0.9$)$ & .74 \\
\hline Low cardiac output syndrome, $* \%(\mathrm{n} / \mathrm{N})$ & $5.7 \%(2 / 35)$ & $0(0 / 33)$ & $-5.7 \%(-29.2$ to 18.5$)$ & .49 \\
\hline Reoperation, $\%(\mathrm{n} / \mathrm{N})$ & $17.1 \%(6 / 35)$ & $9.1 \%(3 / 33)$ & $-8.0 \%(-30.5$ to 16.3$)$ & .47 \\
\hline Antimicrobial changed, $\uparrow \%(\mathrm{n} / \mathrm{N})$ & $94.3 \%(33 / 35)$ & $100 \%(33 / 33)$ & $5.7 \%(-18.5$ to 29.2$)$ & .49 \\
\hline Atrial fibrillation, $\%(\mathrm{n} / \mathrm{N})$ & $31.4 \%(11 / 35)$ & $33.3 \%(11 / 33)$ & $1.9 \%(-22.1$ to 24.9$)$ & 1.00 \\
\hline $\begin{array}{l}\text { Ventricular fibrillation or ventricular tachycardia, } \\
\%(\mathrm{n} / \mathrm{N})\end{array}$ & $2.9 \%(1 / 35)$ & $6.1 \%(2 / 33)$ & $3.2 \%(-20.6$ to 27.1$)$ & .61 \\
\hline $\mathrm{CPR}$ for cardiac/respiratory arrest, $\%(\mathrm{n} / \mathrm{N})$ & $0 \%(0 / 35)$ & $0 \%(0 / 33)$ & $0 \%$ & 1.00 \\
\hline Stroke, $\%(\mathrm{n} / \mathrm{N})$ & $2.9 \%(1 / 35)$ & $3.0 \%(1 / 33)$ & $0.1(-4.1$ to 7.9$)$ & 1.00 \\
\hline \multicolumn{5}{|l|}{ Patient-centered outcomes } \\
\hline Alive at ICU discharge, $\%(\mathrm{n} / \mathrm{N})$ & $97.2 \%(35 / 36)$ & $93.9 \%(31 / 33)$ & $-3.2 \%(-26.3$ to 20.5$)$ & .60 \\
\hline Alive at hospital discharge, $\%(\mathrm{n} / \mathrm{N})$ & $97.2 \%(35 / 36)$ & $93.9 \%(31 / 33)$ & $-3.2 \%(-26.3$ to 20.5$)$ & .60 \\
\hline Alive at Day $90, \%(\mathrm{n} / \mathrm{N})$ & $97.2 \%(35 / 36)$ & $93.9 \%(31 / 33)$ & $-3.2 \%(-26.3$ to 20.5$)$ & .60 \\
\hline $\begin{array}{l}\text { RAND-36 General Health, reported by survivors } \\
\text { at day } 90, \text { mean (SD) }\end{array}$ & $\begin{array}{l}67.1(27.6) \\
35 \text { survivors }\end{array}$ & $\begin{array}{l}54.8(26.2) \\
31 \text { survivors }\end{array}$ & $-12.3(-0.97$ to 25.5$)$ & .07 \\
\hline $\begin{array}{l}\text { RAND-36 Physical Function, reported by } \\
\text { survivors at day } 90, \text { mean (SD) }\end{array}$ & $\begin{array}{l}71.9(30.5) \\
35 \text { survivors }\end{array}$ & $\begin{array}{l}63.9(26.5) \\
31 \text { survivors }\end{array}$ & $-8.0(-22.0$ to 6.0$)$ & .26 \\
\hline $\begin{array}{l}\text { ECOG performance status, reported by survivors } \\
\text { at day } 90, \text { mean (SD) }\end{array}$ & $\begin{array}{l}0.80(0.96) \\
35 \text { survivors }\end{array}$ & $\begin{array}{l}0.83(0.69) \\
31 \text { survivors }\end{array}$ & $0.04(-0.37$ to 0.45$)$ & .85 \\
\hline
\end{tabular}

$C I$, Confidence interval; $S D$, standard deviation; $C A B G$, coronary artery bypass graft; $N / A$, not available; $I C U$, intensive care unit; $H D U$, high-dependency unit; $C P R$, cardiopulmonary resuscitation; RAND-36, Public domain version of the Short Form 36; ECOG, Eastern Collaborative Oncology Group. *Defined as cardiac index less than $2 \mathrm{~L} / \mathrm{min} / \mathrm{m}^{2}$ with objective signs of an imbalance between oxygen delivery and oxygen consumption $(\mathrm{pH}<7.3)$. $\dagger$ Antimicrobial changed during ICU/HDU stay, indicating concern regarding potential infection.

stipulated on-pump surgery as an explicit eligibility criterion.

Another potential limitation of this study is that the intervention was not blinded. However, measures of renal function were based on objective assays conducted by a central lab that was unaware of treatment allocation. In addition, treatments such as use of diuretics and provision of RRT did not differ between study groups. There is no objective evidence of bias arising due to lack of intervention blinding.

Although the standard assay for serum creatinine, and estimation of GFR using creatinine-based equations, may be biased by large positive shifts in fluid balance, creatinine unadjusted for fluid balance remains the clinical standard for the diagnosis of cardiac surgery-associated $\mathrm{AKI}^{3,26}$ Failure to adjust for large positive fluid balances inherent with cardiac surgery may result in the underdiagnosis of AKI and over-estimation of eGFR. ${ }^{33}$ Since fluid intake and net fluid balance did not differ between randomized groups (Table 2), it is unlikely that failure to adjust for accumulated fluid balance resulted in false positive results.

\section{Caveat for Future Research}

It is important to recognize that metabolism of the study amino acid supplement led to a statistically significant increase in blood urea levels (ureagenesis). Future investigators need to be cautioned to monitor blood urea 


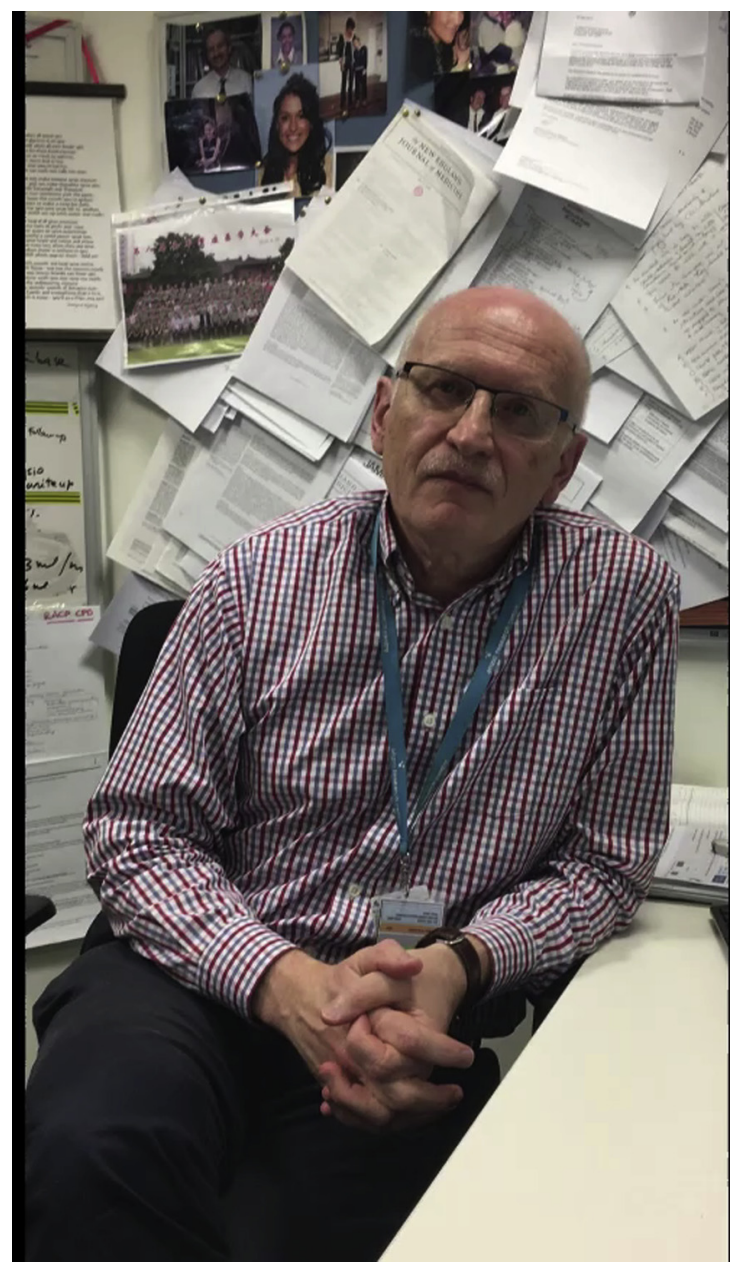

VIDEO 1. Prof Rinaldo Bellomo talks about the project. Video available at: https://www.jtcvs.org/article/S0022-5223(18)33243-4/fulltext.

levels closely. If clinicians become concerned, we strongly recommend the study intervention should be stopped to give urea a chance to clear before RRT is considered.

\section{CONCLUSIONS}

As defined by the 2016 extension to the CONSORT statement, the purpose of a pilot trial is "to support the development of a future definitive RCT." 14 This small pilot trial demonstrates that the provision of the study intervention, an amino acid infusion commenced after the induction of anesthesia, is feasible and achieves a significant increase in protein intake during the first 3 postoperative days. Although the study intervention did not alter duration of renal dysfunction, it did result in a significant reduction in the duration of AKI and also resulted in improvements in other key measures of renal function. Because the clinical relevance of these improvements in renal function remains unclear, these findings warrant confirmation by the conduct of multi-center clinical trials adequately powered to detect improvements in patient-centered outcomes.

\section{Conflict of Interest Statement}

Dr Doig reports receiving academic research grants from Fresenius Kabi Deutschland $\mathrm{GmbH}$ and Baxter Healthcare Pty Ltd and speakers honoraria from Fresenius Kabi Deutschland $\mathrm{GmbH}$, Baxter Healthcare Australia, Pty Ltd, Nestle Healthcare, Vevy, Switzerland, and Nutricia Pharmaceutical (Wuxi) Co, Ltd, China. Dr Allingstrup reports receiving academic research grants from Fresenius Kabi Deutschland GmbH, Medinor A/S Denmark, and COSMED Irl, Rome, Italy, and speakers honoraria from Fresenius Kabi A/S Denmark, Baxter Healthcare A/S Denmark, and Nutricia A/S Denmark. Dr Pollock reports receiving consulting fees from Baxter Healthcare Pty, Ltd, on an unrelated research project. All other authors have nothing to disclose with regard to commercial support.

Heart Research Australia, The University of Sydney's Cardiothoracic Research Scheme, and/or Baxter Healthcare Pty, Ltd, played no role in the design or conduct of the study; the collection, management, analysis, and interpretation of the data; or the preparation, review, or approval of the manuscript. Although the participating site was compensated for the costs of conducting the trial, site investigators did not receive financial compensation for their contributions.

\section{References}

1. Hobson CE, Yavas S, Segal MS, Schold JD, Tribble CG, Layon AJ, et al Acute kidney injury is associated with increased long-term mortality after cardiothoracic surgery. Circulation. 2009;119:2444-53.

2. Alshaikh HN, Katz NM, Gani F, Nagarajan N, Canner JK, Kacker S, et al. Financial impact of acute kidney injury after cardiac operations in the United States. Ann Thorac Surg. 2018:105:469-75.

3. Wang Y, Bellomo R. Cardiac surgery-associated acute kidney injury: risk factors, pathophysiology and treatment. Nat Rev Nephrol. 2017;13:697-711.

4. Lannemyr L, Bragadottir G, Krumbholz V, Redfors B, Sellgren J, Ricksten SE. Effects of cardiopulmonary bypass on renal perfusion, filtration, and oxygenation in patients undergoing cardiac surgery. Anesthesiology. 2017;126:205-13.

5. Zarbock A, Schmidt C, Van AH, Wempe C, Martens S, Zahn PK, et al. Effect of remote ischemic preconditioning on kidney injury among high-risk patients undergoing cardiac surgery: a randomized clinical trial. JAMA. 2015;313: 2133-41.

6. Woods LL. Mechanisms of renal hemodynamic regulation in response to protein feeding. Kidney Int. 1993;44:659-75.

7. Brezis M, Silva P, Epstein FH. Amino acids induce renal vasodilatation in isolated perfused kidney: coupling to oxidative metabolism. Am J Physiol. 1984;247(6 Pt 2):H999-1004.

8. Fliser D, Zeier M, Nowack R, Ritz E. Renal functional reserve in healthy elderly subjects. J Am Soc Nephrol. 1993;3:1371-7.

9. Sharma A, Zaragoza JJ, Villa G, Ribeiro LC, Lu R, Sartori M, et al. Optimizing a kidney stress test to evaluate renal functional reserve. Clin Nephrol. 2016;86: 18-26.

10. Roberts PR, Black KW, Zaloga GP. Enteral feeding improves outcome and protects against glycerol-induced acute renal failure in the rat. Am J Respir Crit Care Med. 1997; 156:1265-9.

11. De Moor B, Vanwalleghem JF, Swennen Q, Stas KJ, Meijers BKI Haemodynamic or metabolic stimulation tests to reveal the renal functional response: requiem or revival? Clin Kidney J. 2018;11:623-54.

12. Gabbai FB. The role of renal response to amino acid infusion and oral protein load in normal kidneys and kidney with acute and chronic disease. Curr Opin Nephrol Hypertens. 2018;27:23-9.

13. Jeppsson A, Ekroth R, Friberg P, Kirno K, Milocco I, Nilsson F, et al. Renal effects of amino acid infusion in cardiac surgery. J Cardiothorac Vasc Anesth 2000;14:51-5. 
14. Eldridge SM, Chan CL, Campbell MJ, Bond CM, Hopewell S, Thabane L, et al. CONSORT 2010 statement: extension to randomised pilot and feasibility trials. BMJ. 2016;355:i5239.

15. Schulz KF, Grimes DA. Allocation concealment in randomised trials: defending against deciphering. Lancet. 2002;359:614-8.

16. Simpson F, Sweetman EA, Doig GS. A systematic review of techniques and interventions for improving adherence to inclusion and exclusion criteria during enrolment into randomised controlled trials. Trials. 2010;11:17.

17. Bernard GR, Doig GS, Hudson LD, Lemeshow S, Marshall JC, Russel J, et al. Quantification of organ failure for clinical trials and clinical practice. Am J Respir Crit Care Med. 1995; 151:A323.

18. Vincent JL, Moreno R, Takala J, Willatts S, De MA, Bruining H, et al. The SOFA (Sepsis-related Organ Failure Assessment) score to describe organ dysfunction/failure. On behalf of the Working Group on Sepsis-Related Problems of the European Society of Intensive Care Medicine. Intensive Care Med. 1996;22:707-10.

19. Kellum JA, Lameire N. Diagnosis, evaluation, and management of acute kidney injury: a KDIGO summary (Part 1). Crit Care. 2013;17:204.

20. Levey AS, Stevens LA, Schmid CH, Zhang YL, Castro AF III, Feldman HI, et al. A new equation to estimate glomerular filtration rate. Ann Intern Med. 2009;150:604-12.

21. Stevens LA, Coresh J, Schmid CH, Feldman HI, Froissart M, Kusek J, et al Estimating GFR using serum cystatin $\mathrm{C}$ alone and in combination with serum creatinine: a pooled analysis of 3,418 individuals with CKD. Am J Kidney Dis. 2008:51:395-406.

22. Zubrod C, Schneiderman MA, Frei E, Brindley C, Gold GL, Shnider B, et al Appraisal of methods for the study of chemotherapy of cancer in man: comparative therapeutic trial of nitrogen mustard and triethylene thiophosphoramide. J Chronic Dis. 1960;11:7-33.

23. Ware JE Jr, Sherbourne CD. The MOS 36-item short-form health survey (SF-36) I. Conceptual framework and item selection. Med Care. 1992:30:473-83.

24. Doig GS, Simpson F, Finfer S, Delaney A, Davies AR, Mitchell I, et al. Effect of evidence-based feeding guidelines on mortality of critically ill adults: a cluster randomized controlled trial. JAMA. 2008;300:2731-41.
25. Doig GS, Simpson F, Sweetman EA, Heighes PT, on behalf of the Nephro-Protective Trial Management Committee. Statistical Analysis Plan for a multi-centre randomised controlled trial: nephro-protective effects of L-amino acids in critically ill patients. Sydney: EvidenceBased.net; 2013. Available at: https://secure.evidencebased.net/login/nephroprotect/NephroProtect_SAP.pdf. Accessed January 4, 2019.

26. Garg AX, Devereaux PJ, Yusuf S, Cuerden MS, Parikh CR, Coca SG, et al. Kidney function after off-pump or on-pump coronary artery bypass graft surgery: a randomized clinical trial. JAMA. 2014;311:2191-8.

27. Bosch JP, Saccaggi A, Lauer A, Ronco C, Belledonne M, Glabman S. Renal functional reserve in humans. Effect of protein intake on glomerular filtration rate. Am J Med. 1983;75:943-50.

28. Brown JR, Kramer RS, Coca SG, Parikh CR. Duration of acute kidney injury impacts long-term survival after cardiac surgery. Ann Thorac Surg. 2010;90:1142-8.

29. Swaminathan M, Hudson CC, Phillips-Bute BG, Patel UD, Mathew JP, Newman MF, et al. Impact of early renal recovery on survival after cardiac surgery-associated acute kidney injury. Ann Thorac Surg. 2010;89:1098-104.

30. Xu JR, Zhu JM, Jiang J, Ding XQ, Fang Y, Shen B, et al. Risk factors for long-term mortality and progressive chronic kidney disease associated with acute kidney injury after cardiac surgery. Medicine (Baltimore). 2015;94:e2025.

31. Wang V, Vilme H, Maciejewski ML, Boulware LE. The economic burden of chronic kidney disease and end-stage renal disease. Semin Nephrol. 2016;36:319-30.

32. Nimdet K, Chaiyakunapruk N, Vichansavakul K, Ngorsuraches S. A systematic review of studies eliciting willingness-to-pay per quality-adjusted life year: does it justify CE threshold? PLoS One. 2015;10:e0122760.

33. Macedo E, Bouchard J, Soroko SH, Chertow GM, Himmelfarb J, Ikizler TA, et al. Fluid accumulation, recognition and staging of acute kidney injury in critically-ill patients. Crit Care. 2010;14:R82.

Key Words: randomized controlled trial, acute kidney injury, cardiac surgery, amino acids, pilot 